\title{
The Influence of Abutment Surface Treatment and the Type of Luting Cement on Shear Bond Strength between Titanium/Cement/Zirconia
}

\author{
Beata Śmielak, ${ }^{1}$ Marcin Gołębiowski, ${ }^{1}$ and Leszek Klimek ${ }^{2,3}$ \\ ${ }^{1}$ Department of Prosthodontics, Medical University of Łódź, Ulica Pomorska 251, 92-213 Łódź, Poland \\ ${ }^{2}$ Department of Materials Science, Institute of Materials Engineering, Lodz University of Technology, Ulica Stefanowskiego 1/15, \\ 90-924 Łódź, Poland \\ ${ }^{3}$ Department of Dental Laboratory Technology, Medical University of Łódź, 92-213 Łódź, Poland
}

Correspondence should be addressed to Beata Śmielak; bsmielak@hotmail.com

Received 10 June 2015; Revised 25 August 2015; Accepted 4 October 2015

Academic Editor: Luciano Lamberti

Copyright (C) 2015 Beata Śmielak et al. This is an open access article distributed under the Creative Commons Attribution License, which permits unrestricted use, distribution, and reproduction in any medium, provided the original work is properly cited.

Objectives. The objectives of this study were to evaluate the shear bond strength of zirconia cylinders on a modified titanium surface using different luting cement types. Material and Methods. Eighty titanium disks were divided into two groups $(n=40)$, which were treated with either grinding or a combination of sandblasting and grinding. Then, each group was subdivided into 4 groups $(n=10)$ and the disks were bonded to disks of sintered zirconia using one of four cement types (permanent: composite cement; temporary: polycarboxylate cement, zinc-oxide-eugenol cement, and resin cement). Shear bond strength (SBS) was measured in a universal testing machine. Fracture pattern and site characteristic were recorded. A fractographic analysis was performed with SEM. The chemical analysis of the composition of the fractures was performed using energy-dispersive X-ray spectroscopy (EDS). The results of the experiment were analyzed with two-way analysis of variance and Tukey post hoc test. Results. The highest mean values of SBS were achieved when grinding was combined with sandblasting and when composite cement was used (18.18 MPa). In the temporary cement group, the highest mean values of SBS were for polycarboxylate cement after grinding (3.57 MPa). Conclusion. The choice of cement has a crucial influence on the titanium-cement-zirconia interface quality.

\section{Introduction}

Dental implants have become the fundamental solution for the restoration of missing teeth in modern prosthodontics [1]. A major advantage of dental implants over conventional tooth supported fixed partial dentures is tooth tissue conservation as adjacent teeth do not need to be prepared. Patients are generally reluctant to wear removable dentures, mainly because of limited oral comfort and/or adaptation problems [2]. Currently, the most suitable material for the production of dental implants is titanium and its alloys $[3,4]$.

Higher aesthetic expectations of patients and the development of CAD/CAM technology have increased the interest in all-ceramic crowns and bridges in dental practice [5-9]. Prosthodontics restorations made of zirconia exhibit the best mechanical properties among all-ceramic restorations [7]. However, their incredible hardness and difficulties with their correct conditioning for cementation make their use problematic [10-19]. Moreover, access to the internal part of the crown is limited, especially in crowns designed for implants, which have a small vestibular/lingual diameter, even if they are correctly designed.

However, both the dental laboratory technician and the dentist have excellent access to the surface of titanium abutments, which are routinely milled in order to assume the correct shape required of an abutment. Moreover, the titanium abutment modifications may be more amenable to modification because of access as well as material properties that affect structural strength less than the zirconia crown. A survey of US dental schools reported that $26 \%$ of dentists do not alter 
the surface of the abutments before cementation, $23 \%$ create grooves for better retention, $16 \%$ perform sandblasting, $6 \%$ use metal primers, and $3 \%$ grind the surface of the abutment with rotary instruments [20].

There is a great variety of luting cement types available on the market. However, there are insufficient clear guidelines concerning their use. Moreover, the cement should bond adhesively with the abutments and should be radiopaque and its excess should be easy to remove and should be retrievable. Either implant-specific cement or traditional restoration cement may be used for cementing implant restorations. These kinds of cement have been extensively assessed in terms of mechanical properties, including retention capabilities [21-25]. Cement has also been shown to extrude at the implant-abutment interface, when subgingival margins are present $[26,27]$. According to Tarica et al., 90\% of respondent dentists in the US use resin-modified glass-ionomer materials. Resin, glass-ionomer, and zinc-phosphate cement types are also frequently used. Several respondents indicated that resin cement is used for either zirconium- or aluminumbased abutments [20].

Some professionals argue that temporary cement should allow easy access to abutments and implants [28]. Others use temporary cement types before permanent cementation in the adaptation period in order to evaluate the aesthetic, phonetic, and occlusal stability in the same manner in which they are used in conventional prosthodontics [29]. Others start by using weaker temporary cement and increase bonding strength gradually until the expected values of bond strength are achieved [30]. Such repeated placement and removal with temporary cement do not affect the properties of the final cement retention [31].

The surface properties of the implant and its prosthetic abutments provide one of the most important conditions relating to the future success of implant procedures. Since these components penetrate through the gingival mucosa and are also exposed to the oral cavity, they play an important role not only in biocompatibility but also in bacterial adhesion and stagnation $[32,33]$.

Because of the great variety in luting cement types for implant-based restorations and difficulties with choosing the best option, the bond strengths of the three most frequently used temporary cement types and one permanent cement were chosen. Titanium disks were used for the purpose of the study. They were bonded to elements made of zirconia (3 Y-TPZ) using one of four cement types after treatment. Finding the optimum method of cementation would make it possible to avoid the complications associated with the use of titanium abutments. The aim of the study was to evaluate the influence of surface treatment of titanium elements on shear bond strength with different luting cement types and zirconia. The null hypothesis was that the use of different surface treatments and luting cement would not influence the SBS at the titanium/cement interface.

\section{Material and Methods}

Eighty titanium disks (Tritan CpTi grade 2; Dentaurum, Germany) with a diameter of $21 \mathrm{~mm}$ and a thickness of $5 \mathrm{~mm}$ and sintered zirconia disks (Ceramill Zi; Amann Girrbach AG, Austria) with a diameter of $8 \mathrm{~mm}$ and a thickness of $5 \mathrm{~mm}$ were used in the experiment. The minimum content of titanium was equal to $99.5 \%$ with traces of $\mathrm{Fe}, \mathrm{O}, \mathrm{H}$, and $\mathrm{N}$, according to the classification of the American Society for Testing and Materials. In order to determine the parameters of the treatment, the roughness of the titanium element (the implant abutment) was assessed using a profilometer following preliminary milling and it was established that grinding with $\mathrm{SiC}$ abrasive paper with a grit size of 180 provides roughness analogous to milling. The specimens were ground on a rotary grinder (Metasinex; Metasinex Row, Poland) under water cooling and washed with water and dried with compressed air after each grinding.

Titanium disks were divided into two groups, which were treated by either grinding $(n=40)$ or grinding and sandblasting with aluminum oxide $\left(\mathrm{Al}_{2} \mathrm{O}_{3}\right)$ particle size of $60 \mu \mathrm{m}(n=$ 40) using Mikroblast Duo (Mikroblast; Prodento-Optimed, Germany) under pressure $0.4 \mathrm{MPa}$ at glancing angles of 45 degrees and a distance of $20 \mathrm{~mm}$ for 20 seconds. After the process, titanium disks were cleaned with steam under pressure, washed in deionized water in an ultrasonic cleaning bath for 8 minutes, dried with compressed air, and bonded to zirconia disks with one of four cement types (1 permanent and 3 temporary) (permanent cement type: composite cement (Panavia F 2.0; Kuraray Co., Ltd., Osaka, Japan); temporary cement types: polycarboxylate cement (Adhesor Carbofine; Sybron Dental Specialties/Kerr Corp., Orange, USA), zincoxide-eugenol cement (TempBond; Sybron Dental Specialties/Kerr Corp., Orange, USA), and resin cement (Premier Implant Cement; Premier Products Comp., Plymouth Meeting, USA)). The cement specimens were prepared according to the instructions provided by the manufacturer. The excess material was removed manually using a curette and dental probe.

Shear bond strength (Zwick/Roell Z005, Instron Corp., Germany) was measured to determine the strength of the bonds between titanium, cement, and zirconia. The specimens were loaded at a crosshead speed of $2 \mathrm{~mm} / \mathrm{min}$ until failure of the titanium-cement-zirconia bond; maximum forces were recorded (Figure 1) and, together with the diagrams of the course, were entered into a computer program integrated with testing device. Subsequently, the bond strength was calculated from the following formula: $R t=F / S$, where $R t$ is the shear force $[\mathrm{Pa}], F$ is the force acting on the specimen $[\mathrm{N}]$, and $S$ is the surface area of the specimen $\left[\mathrm{m}^{2}\right]$.

The results were statistically analyzed using $R$ statistical package. The analysis was based on two-way analysis of variance and Tukey post hoc test comparison procedures. After the strength measurements were performed, cross sections of the fractured specimens were analyzed with an electron scanning microscope (SEM S-3000N; Hitachi HighTechnologies Corp., Ltd., Tokyo, Japan) to determine the nature of the fractures formed in the shearing process and the locations where the specimens fractured.

The chemical composition of the fractures was determined by using energy-dispersive X-ray spectroscopy (Thermo Noran Inc., Madison, United States), compatible with the scanning electron microscope Hitachi S-3000N. 
TABLE 1: Shear bond strength at the titanium/cement/zirconia interface [MPa].

\begin{tabular}{|c|c|c|c|c|c|c|c|c|}
\hline \multirow[b]{3}{*}{ Type of cement } & \multicolumn{8}{|c|}{ Treatment variant } \\
\hline & \multicolumn{4}{|c|}{ Grinding } & \multicolumn{4}{|c|}{ Grinding and sandblasting } \\
\hline & Mean & $\begin{array}{l}\text { Standard } \\
\text { deviation }\end{array}$ & $\begin{array}{c}\text { Coefficient of } \\
\text { variation }\end{array}$ & $\begin{array}{l}\text { Standard } \\
\text { error }\end{array}$ & Mean & $\begin{array}{l}\text { Standard } \\
\text { deviation }\end{array}$ & $\begin{array}{c}\text { Coefficient of } \\
\text { variation }\end{array}$ & $\begin{array}{c}\text { Standard } \\
\text { error }\end{array}$ \\
\hline TempBond & 0.50 & 0.27 & 55.08 & 0.10 & 2.67 & 0.60 & 22.58 & 0.25 \\
\hline Adhesor & 3.45 & 1.46 & 42.17 & 0.55 & 2.67 & 1.73 & 65.01 & 0.66 \\
\hline Premier Implant Cement & 1.99 & 0.67 & 33.74 & 0.25 & 3,57 & 1,10 & 30.98 & 0.42 \\
\hline Panavia F 2.0 & 13.25 & 1.93 & 14.56 & 0.73 & 18,18 & 2.53 & 13.94 & 0.96 \\
\hline
\end{tabular}

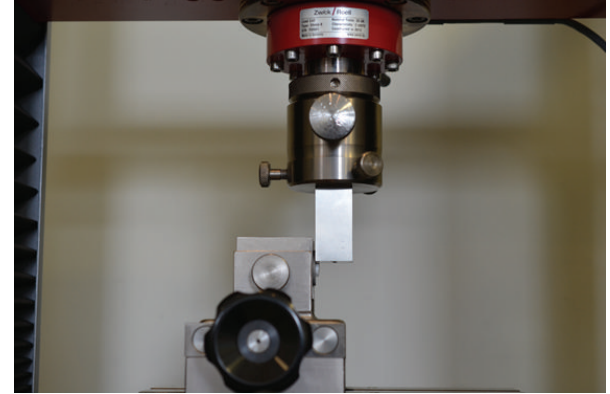

FIGURE 1: Loading frame utilized to perform the shear strength test.

The energy values of characteristic X-rays emitted from the specimens after excitation by a primary electron beam were measured using a semiconductor detector. The acquired spectra enabled qualitative evaluation of chemical elements present in the specimens.

\section{Results}

Statistical analysis of the results of the strength tests (Table 1) showed that the treatment variant used is a highly significant factor $(F(1 ; 47)=24.20, p<0.0001)$ affecting shear bond strength $[\mathrm{MPa}]$. The results are higher when grinding is combined with sandblasting than when grinding is applied alone. The type of cement used also has a very significant $(F(3 ; 47)=277.19, p<0.0001)$ effect on shear bond strength $[\mathrm{MPa}]$. Significant differences were observed between cement types, between each compared pair. The lowest mean shear bond strength results were achieved for TempBond (0.5 MPa), followed by Premier Implant Cement $(1.99 \mathrm{MPa})$ after grinding and followed in turn by Adhesor after grinding and sandblasting (2.67 $\mathrm{MPa})$.

The highest mean shear bond strength result, which was significantly higher than all the others, was achieved when grinding was combined with sandblasting and when Panavia F 2.0 was used (18.18 MPa). When grinding was used in conjunction with Panavia F 2.0, the result was significantly lower than the above, despite being higher than other treatment and cement combinations $(13.25 \mathrm{MPa})$. The interaction between factors is highly significant $(F(3 ; 47)=8.73, p<0.0001)$.

The SBS results were similar for TempBond, Adhesor, and Premier Implant Cement irrespective of the treatment method used. The minimal acceptable shear bond strength of cemented restorations is $13-15 \mathrm{MPa}$ [19]. Only one cement, Panavia, met those criteria.

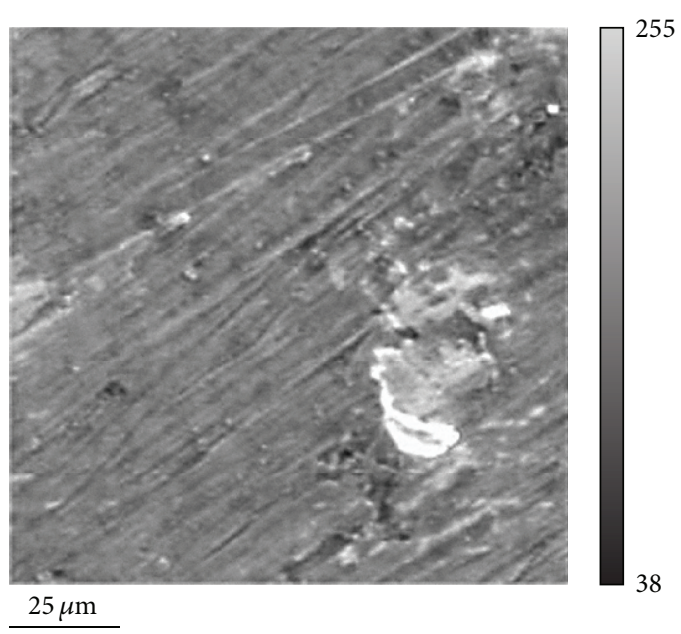

FIGURE 2: SEM micrograph of the titanium surface after grinding treated with cement Panavia F 2.0 (resin cement filler; white arrows: microporosities with no penetration of resin cement). Magnification $\times 500$.

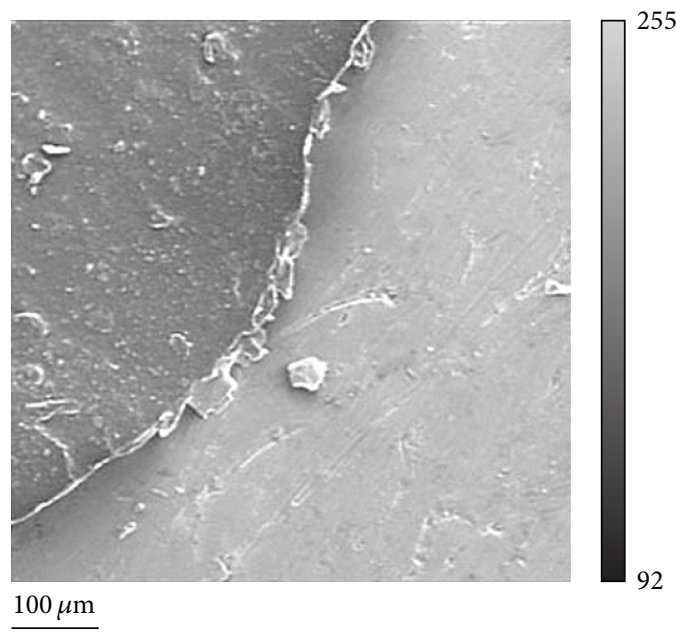

FIGURE 3: SEM micrograph of titanium surface after grinding treated with Adhesor cement. Magnification $\times 500$.

After shear strength testing, cross sections of the fractures were analyzed using SEM. Figures 2, 3, and 4 show examples of micrographs acquired in the analysis. Surface distribution of $\mathrm{C}, \mathrm{O}, \mathrm{Si}$, and $\mathrm{Ti}$ on the titanium surface after grinding treated with cement Panavia F 2.0 is presented in Figure 5. Figure 6 presented the surface distribution of $\mathrm{Ti}, \mathrm{C}, \mathrm{Zn}$, 


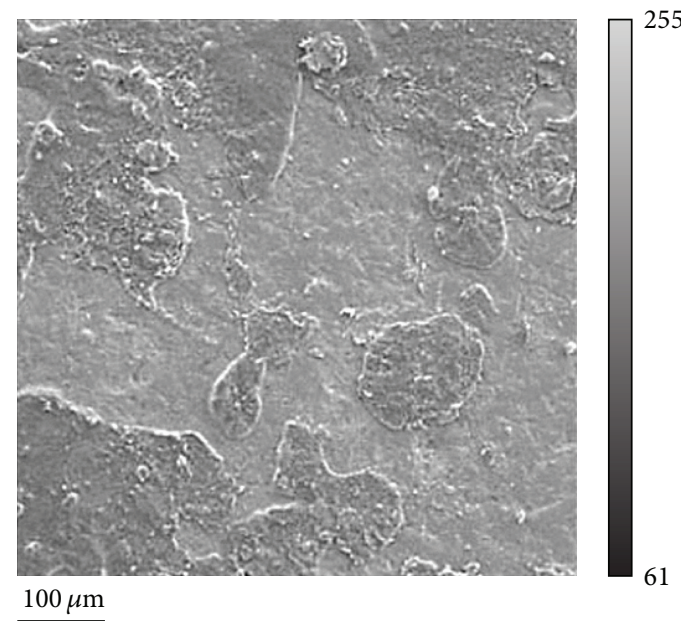

FIGURE 4: SEM micrograph of zirconia surface treated with Adhesor cement. Magnification $\times 500$.

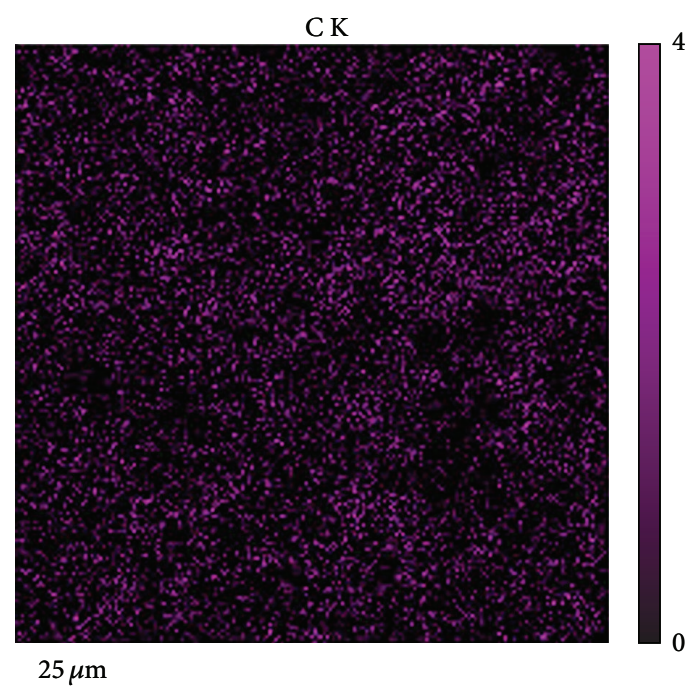

(a)

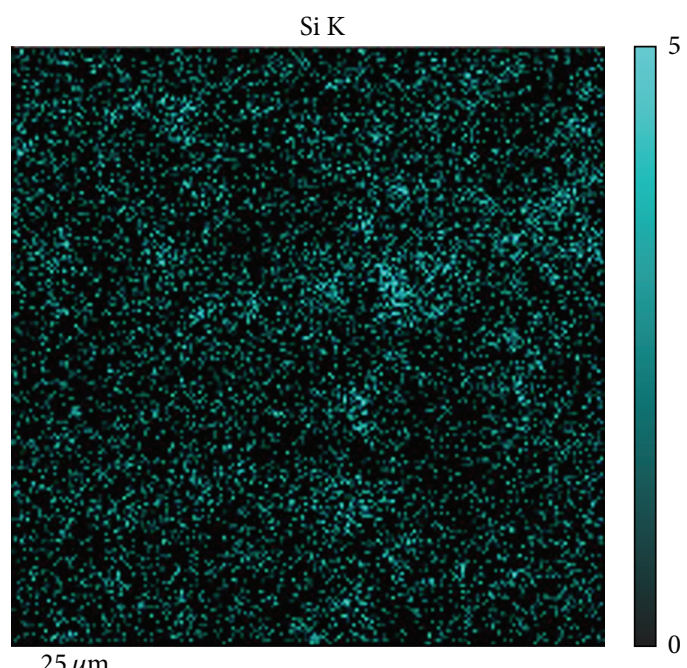

(c)

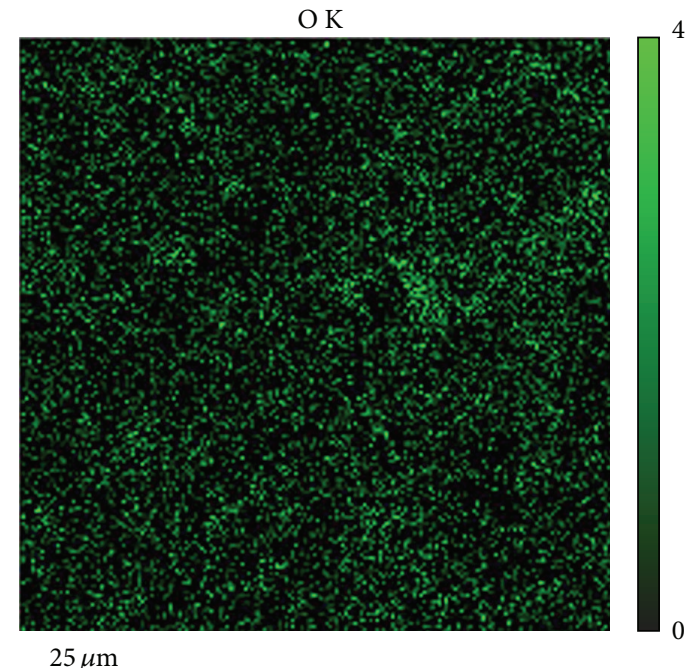

(b)

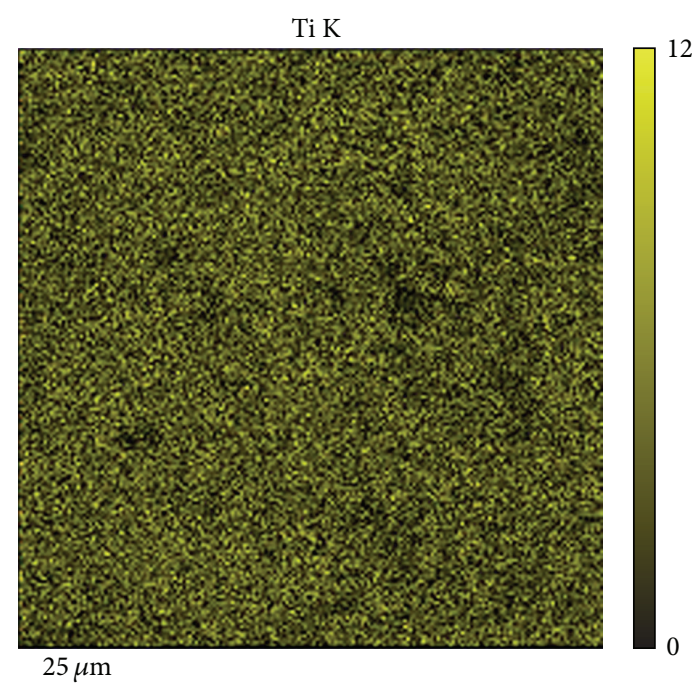

(d)

FIGURE 5: Distribution of elements on surface of titanium specimen after grinding treated with cement Panavia F 2.0. (a) Surface distribution of C. (b) Surface distribution of O. (c) Surface distribution of Si. (d) Surface distribution of Ti. 


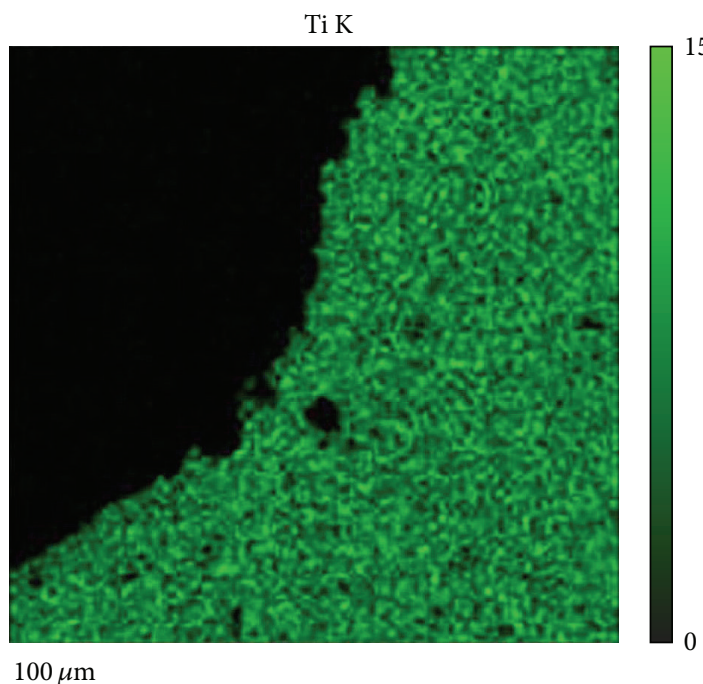

(a)

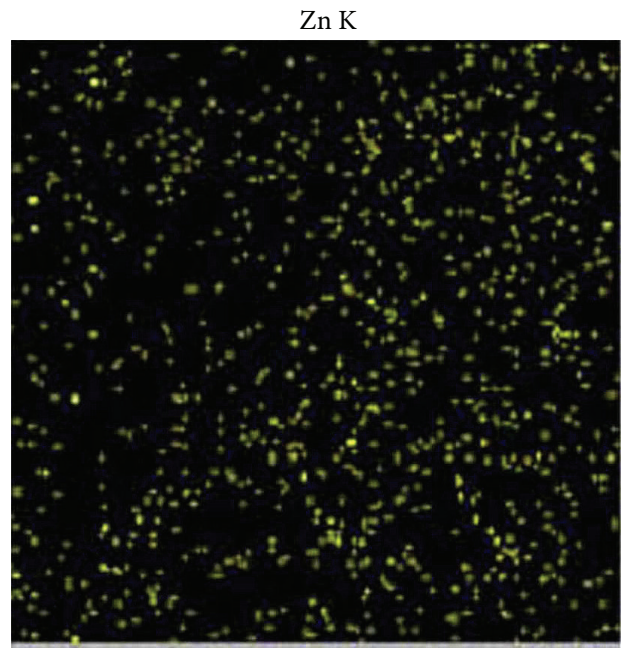

$100 \mu \mathrm{m}$

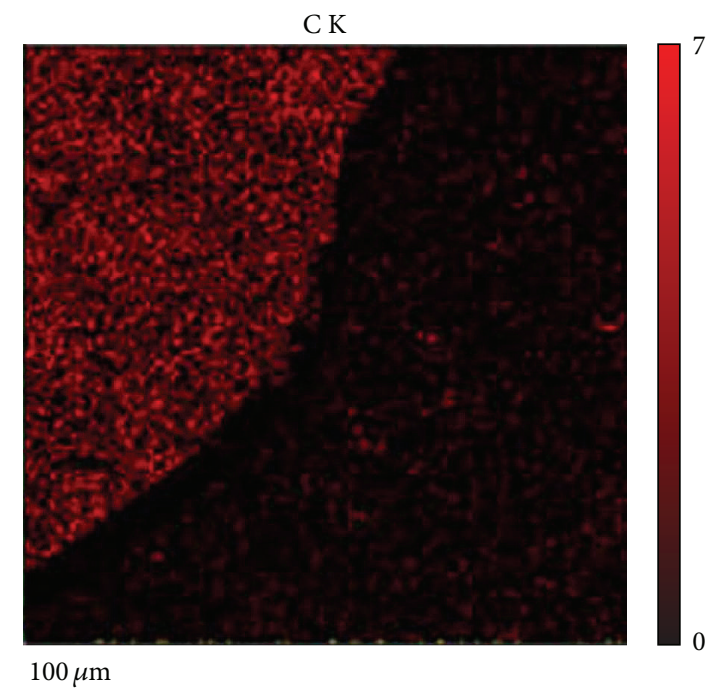

(b)

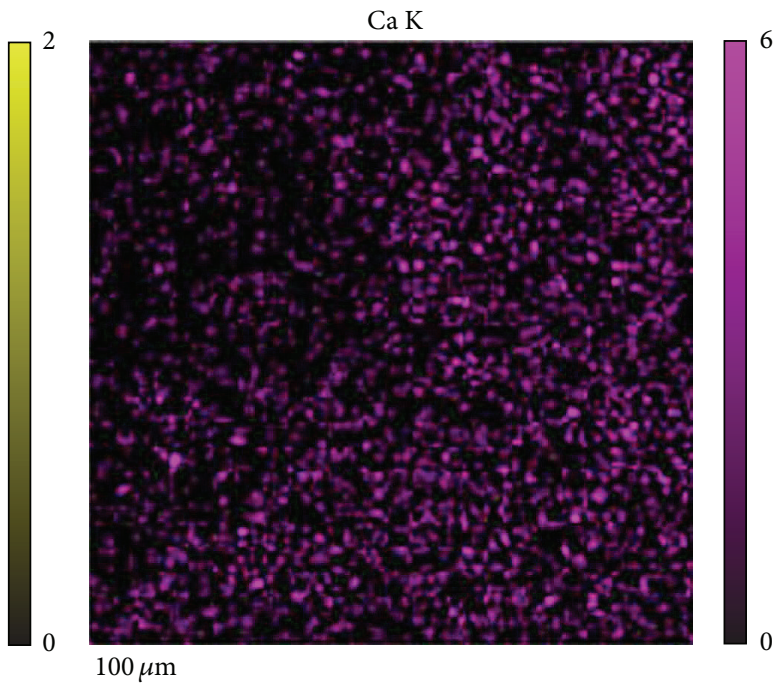

(d)

Figure 6: Distribution of elements on surface of titanium specimen after grinding treated with Adhesor cement. (a) Surface distribution of Ti. (b) Surface distribution of C. (c) Surface distribution of Zn. (d) Surface distribution of Ca.

and $\mathrm{Ca}$ on the titanium surface after grinding treated with Adhesor cement.

Figure 7 presented the same specimen but with surface distribution of $\mathrm{C}, \mathrm{Zr}, \mathrm{Zn}$, and $\mathrm{Ca}$ on the zirconia surface.

The fractographic and chemical analyses of the fracture surface of specimens showed that fractures occurred either at the titanium/cement interface when composite cement was used or in the cement itself, at the titanium/cement and zirconia/cement interface.

Chemical analyses of the surface composition X-ray spectra of the specimen surface were used to establish the chemical composition of cross sections.

\section{Discussion}

The null hypothesis that surface treatment and type of luting cement would not influence the bond strength to titanium was rejected. The research results obtained in this study prove that surface treatment has a strong influence on the shear bond strength of the majority of luting cement types. The highest values were observed in specimens, which were treated with sandblasting and which were bonded using composite luting cement (18.18 MPa). Such results were expected, as composite cement is most frequently used as permanent luting cement. It should be noted that sandblasting of the titanium specimens increased SBS to composite 


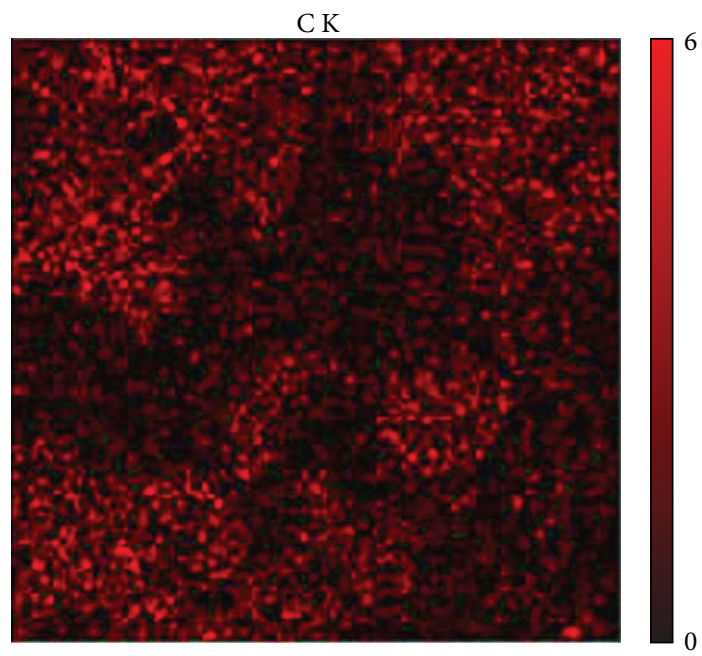

$100 \mu \mathrm{m}$

(a)

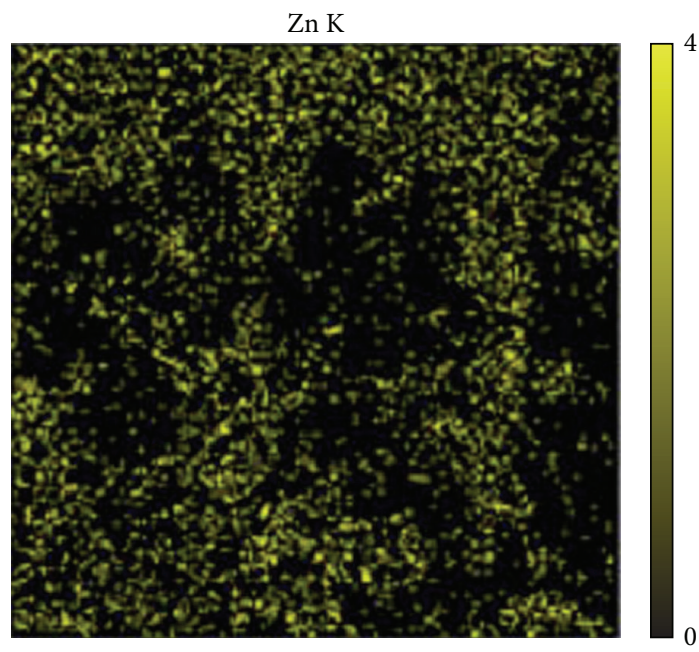
$100 \mu \mathrm{m}$

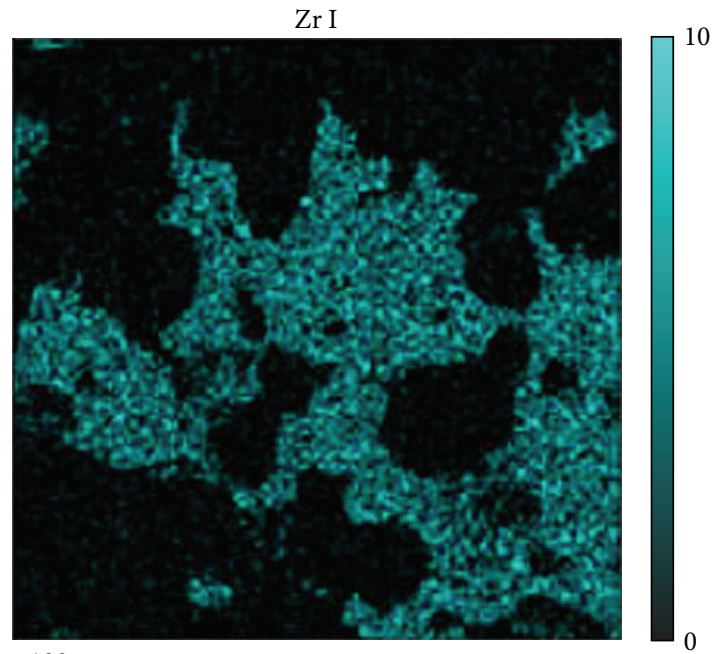

$100 \mu \mathrm{m}$

(b)

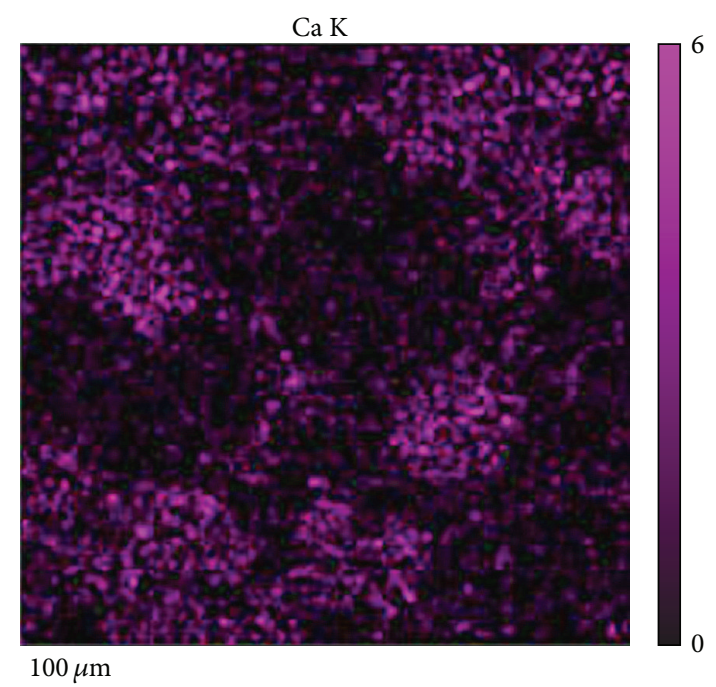

(d)

FIGURE 7: Distribution of elements on surface of zirconia specimen after grinding treated with Adhesor cement. (a) Surface distribution of C. (b) Surface distribution of Zr. (c) Surface distribution of Zn. (d) Surface distribution of Ca.

cement. Taira et al. reported that a suitable durable bonding method to titanium was obtained when the titanium surface was alumina-blasted in combination with a methacrylatephosphate primer and a luting agent [3]. Tsuchimoto et al. concluded that $\mathrm{HCl}$ could be used to effectively improve the adhesive performance of resin to Ti when it is applied in a $1 \mathrm{~N}$ concentration. It is important to note as well that $\mathrm{Ti}$ should not be pretreated with phosphoric acid, because phosphoric acid potentially inhibits the subsequent adsorption of functional monomers onto $\mathrm{Ti}[2]$.

The lowest mean values of SBS were observed for the zincoxide-eugenol cement, TempBond, after grinding (0.5 MPa). However, SBS mean values for this cement increased after grinding and sandblasting $(2.67 \mathrm{MPa})$.
The highest mean values of SBS in the temporary cement group were achieved for Premier Implant Cement after grinding and sandblasting (3.57 MPa).

The increase of SBS of composite cement, resin cement, and zinc-oxide-eugenol cement may be explained by the fact that the surface expands more after both sandblasting and grinding than after grinding only. Micromechanical interlocking seems to be superior for Panavia F 2.0 and is able to flow into the microporosities of the modified titanium surface, filling the micropores with composite resin matrix and filler particles (Figure 2). However, such a relationship cannot be drawn for polycarboxylate cement, Adhesor.

Attention should be paid to the microscopic and chemical composition analyses of the cross sections of the specimens. 
The analyses have shown that the connection broke at the titanium-cement interface when composite cement was used (adhesive failures). The presence of areas rich in silica and oxygen (ingredients of the cement) proves the presence of the residues of the cement and shows that the fracture line could be traced through the cement itself (cohesive failures).

In the case of temporary luting cement, the bond broke both at the titanium-cement interface and at the zirconium oxide-cement interface.

The limitation of this study includes the selection of the test specimen geometry used to measure joint strength. However, the specimen geometry was selected to suit the study methodology; in particular, it had to allow the specimens to be mounted in a strength-testing machine. This study did not include the investigation of all mechanical and physical properties of the studied cement materials. Additionally, the influence of other factors such as $\mathrm{pH}$ changes, long-term water aging, and dynamic fatigue loading, which were not evaluated in the present study, must be investigated to affirm the performance of the studied materials.

\section{Conclusions}

The conclusions are as follows:

(1) The highest values of tensile bond strength were achieved for composite cement Panavia F 2.0. Fractures occurred at the titanium-cement interface.

(2) Temporary luting cement exhibited considerably lower values of bond strength. The fractures of the specimens occurred both at the interface with titanium and with zirconia.

(3) The cement choice has a crucial influence on the titanium-cement-zirconia interface quality.

(4) Surface treatment of titanium (grinding, sandblasting) has considerable influence on the shear bond strength between the cement Panavia F 2.0 and zirconia. Sandblasting increases shear bond strength.

\section{Conflict of Interests}

The authors declare that there is no conflict of interests regarding the publication of this paper.

\section{References}

[1] B. Śmielak and A. Śmielak, "Titanium-alternative materialin prosthodontics," Stomat Współ, vol. 5, pp. 51-54, 2000.

[2] Y. Tsuchimoto, Y. Yoshida, M. Takeuchi et al., "Effect of surface pre-treatment on durability of resin-based cements bonded to titanium," Dental Materials, vol. 22, no. 6, pp. 545-552, 2006.

[3] Y. Taira, H. Matsumura, K. Yoshida, T. Tanaka, and M. Atsuta, "Influence of surface oxidation of titanium on adhesion," Journal of Dentistry, vol. 26, no. 1, pp. 69-73, 1998.

[4] Z. Cai, H. Nakajima, M. Woldu, A. Berglund, M. Bergman, and T. Okabe, "In vitro corrosion resistance of titanium made using different fabrication methods," Biomaterials, vol. 20, no. 2, pp. 183-190, 1999.
[5] H. Tejchman and J. Rabenda, "The role of titanium in dentaltreatment," Mag Stomat, vol. 5, pp. 10-15, 1999.

[6] K. Akagi, Y. Okamoto, T. Matsuura, and T. Horibe, "Properties of test metal ceramic titanium alloys," The Journal of Prosthetic Dentistry, vol. 68, no. 3, pp. 462-467, 1992.

[7] S. Reich, A. Petschelt, and U. Lohbauer, "The effect of finish line preparation and layer thickness on the failure load and fractography of $\mathrm{ZrO}_{2}$ copings," Journal of Prosthetic Dentistry, vol. 99, no. 5, pp. 369-376, 2008.

[8] L. Rutten and P. Rutten, "New horizons in aesthetic implantology," Quintessence Periodontologia-Implanty, vol. 1, pp. 61-79, 2009.

[9] J. Tinschert, D. Zwez, R. Marx, and K. J. Anusavice, "Structural reliability of alumina-, feldspar-, leucite-, mica- and zirconiabased ceramics," Journal of Dentistry, vol. 28, no. 7, pp. 529-535, 2000.

[10] R. C. Oyagüe, F. Monticelli, M. Toledano, E. Osorio, M. Ferrari, and R. Osorio, "Effect of water aging on microtensile bond strength of dual-cured resin cements to pre-treated sintered zirconium-oxide ceramics," Dental Materials, vol. 25, no. 3, pp. 392-399, 2009.

[11] R. C. de Oyagüe, F. Monticelli, M. Toledano, E. Osorio, M. Ferrari, and R. Osorio, "Influence of surface treatments and resin cement selection on bonding to densely-sintered zirconiumoxide ceramic," Dental Materials, vol. 25, no. 2, pp. 172-179, 2009.

[12] R. P. Palacios, G. H. Johnson, K. M. Phillips, and A. J. Raigrodski, "Retention of zirconium oxide ceramic crowns with three types of cement," Journal of Prosthetic Dentistry, vol. 96, no. 2, pp. 104-114, 2006.

[13] S. M. Wegner and M. Kern, "Long-term resin bond strength to zirconia ceramic," Journal of Adhesive Dentistry, vol. 2, no. 2, pp. 139-147, 2000.

[14] M. Guazzato, L. Quach, M. Albakary, and M. V. Swain, "Strength and reliability of surface treated Y-TP dental ceramics," Journal of Biomedical Materials Research B: Applied Biomaterials, vol. 53, no. 4, pp. 304-313, 2000.

[15] T. Kosmač, C. Oblak, P. Jevnikar, N. Funduk, and L. Marion, "The effect of surface grinding and sandblasting on flexural strength and reliability of Y-TZP zirconia ceramic," Dental Materials, vol. 15, no. 6, pp. 426-433, 1999.

[16] A. A. Xible, R. R. de Jesus Tavarez, C. D. R. P. de Araujo, and W. C. Bonachela, "Effect of silica coating and silanization on flexural and composite-resin bond strengths of zirconia posts: an in vitro study," Journal of Prosthetic Dentistry, vol. 95, no. 3, pp. 224-229, 2006.

[17] S. S. Atsu, M. A. Kilicarslan, H. C. Kucukesmen, and P. S. Aka, "Effect of zirconium-oxide ceramic surface treatments on the bond strength to adhesive resin," Journal of Prosthetic Dentistry, vol. 95, no. 6, pp. 430-436, 2006.

[18] M. Kern and S. M. Wegner, "Bonding to zirconia ceramic: adhesion methods and their durability," Dental Materials, vol. 14, no. 1, pp. 64-71, 1998.

[19] J. Y. Thompson, B. R. Stoner, J. R. Piascik, and R. Smith, "Adhesion/cementation to zirconia and other non-silicate ceramics: where are we now?" Dental Materials, vol. 27, no. 1, pp. 71-82, 2011.

[20] D. Y. Tarica, V. M. Alvarado, and S. T. Truong, "Survey of United States dental schools on cementation protocols for implant crown restorations," Journal of Prosthetic Dentistry, vol. 103, no. 2, pp. 68-79, 2010. 
[21] K. X. Michalakis, A. L. Pissiotis, and H. Hirayama, "Cement failure loads of 4 provisional luting agents used for the cementation of implant-supported fixed partial dentures," International Journal of Oral and Maxillofacial Implants, vol. 15, no. 4, pp. 545$549,2000$.

[22] J. L. Sheets, C. Wilcox, and T. Wilwerding, "Cement selection for cement-retained crown technique with dental implants," Journal of Prosthodontics, vol. 17, no. 2, pp. 92-96, 2008.

[23] A. Mansour, C. Ercoli, G. Graser, R. Tallents, and M. Moss, "Comparative evaluation of casting retention using the ITI solid abutment with six cements," Clinical Oral Implants Research, vol. 13, no. 4, pp. 343-348, 2002.

[24] Y.-H. Pan, L. C. Ramp, C.-K. Lin, and P.-R. Liu, "Retention and leakage of implant-supported restorations luted with provisional cement: a pilot study," Journal of Oral Rehabilitation, vol. 34, no. 3, pp. 206-212, 2007.

[25] R. C. Fraga, L. R. L. Luca-Fraga, and L. A. F. Pimenta, "Physical properties of resinous cements: an in vitro study," Journal of Oral Rehabilitation, vol. 27, no. 12, pp. 1064-1067, 2000.

[26] C. Wadhwani, D. Rapoport, S. La Rosa, T. Hess, and S. Kretschmar, "Radiographic detection and characteristic patterns of residual excess cement associated with cement-retained implant restorations: a clinical report," Journal of Prosthetic Dentistry, vol. 107, no. 3, pp. 151-157, 2012.

[27] C. Wadhwani, T. Hess, T. Faber, A. Piñeyro, and C. S. K. Chen, "A descriptive study of the radiographic density of implant restorative cements," The Journal of Prosthetic Dentistry, vol. 103, no. 5, pp. 295-302, 2010.

[28] M. H. Ramp, D. L. Dixon, L. C. Ramp, L. C. Breeding, and L. L. Barber, "Tensile bond strengths of provisional luting agents used with an implant system," Journal of Prosthetic Dentistry, vol. 81, no. 5, pp. 510-514, 1999.

[29] P. Yvan and B. Yuray, "Swedge-in prosthesis: get the advantages of both screw-in and cement-in techniques," Oral Health Journal, vol. 92, no. 8, pp. 25-32, 2002.

[30] H. B. Dumbrigue, A. A. Abanomi, and L. L. Cheng, "Techniques to minimize excess luting agent in cement-retained implant restorations," Journal of Prosthetic Dentistry, vol. 87, no. 1, pp. 112-114, 2002.

[31] L. C. Breeding, D. L. Dixon, M. T. Bogacki, and J. D. Tietge, "Use of luting agents with an implant system: part I," The Journal of Prosthetic Dentistry, vol. 68, no. 5, pp. 737-741, 1992.

[32] B. Kasemo, "Biocompatibility of titanium implants: surface science aspects," The Journal of Prosthetic Dentistry, vol. 49, no. 6, pp. 832-837, 1983.

[33] T. Sawase, A. Wennerberg, C. Hallgren, T. Albrektsson, and K. Baba, "Chemical and topographical surface analysis of five different implant abutments," Clinical Oral Implants Research, vol. 11, no. 1, pp. 44-50, 2000. 

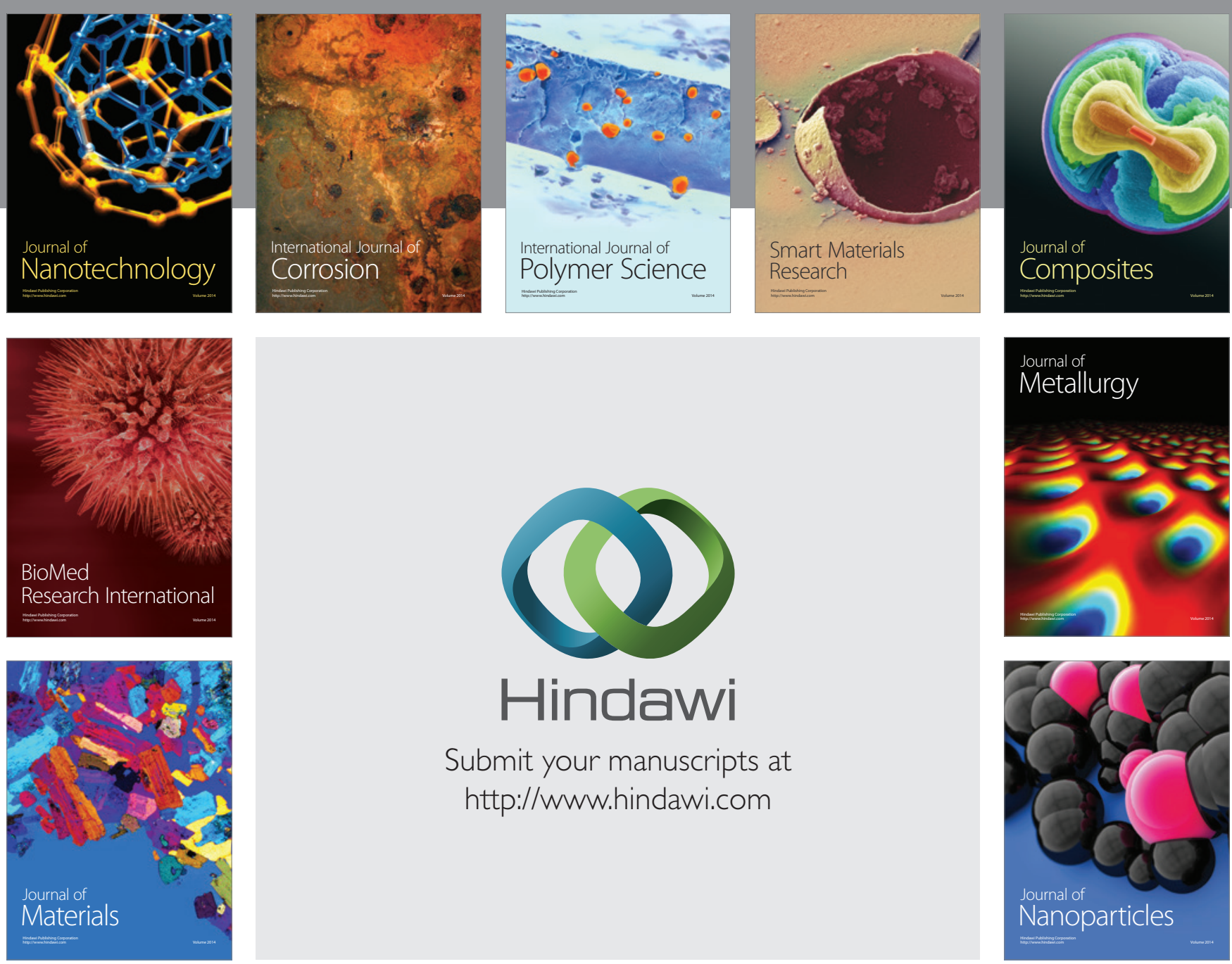

Submit your manuscripts at http://www.hindawi.com
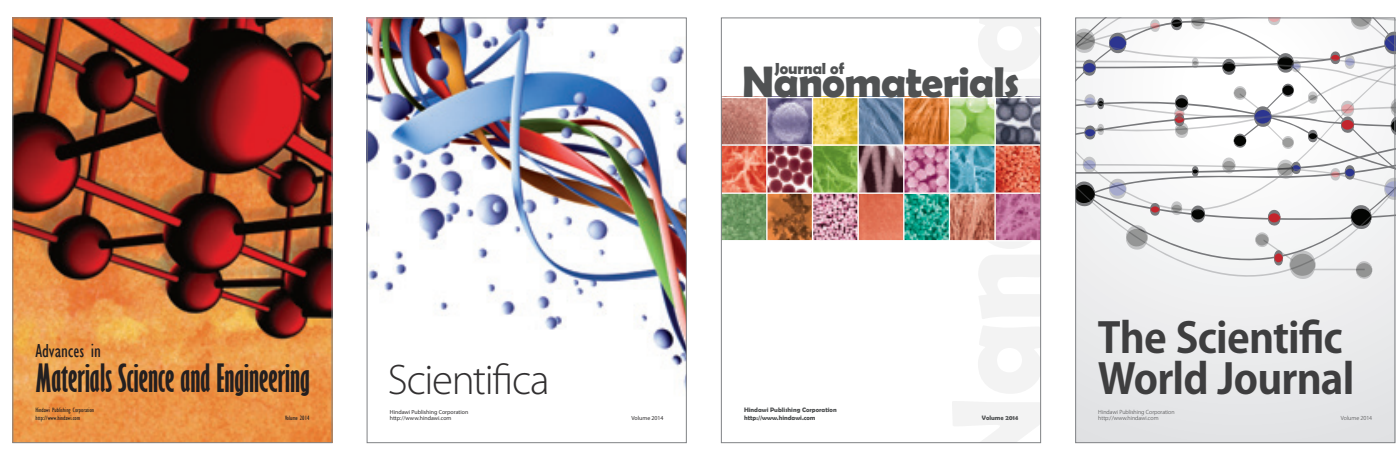

\section{The Scientific World Journal}
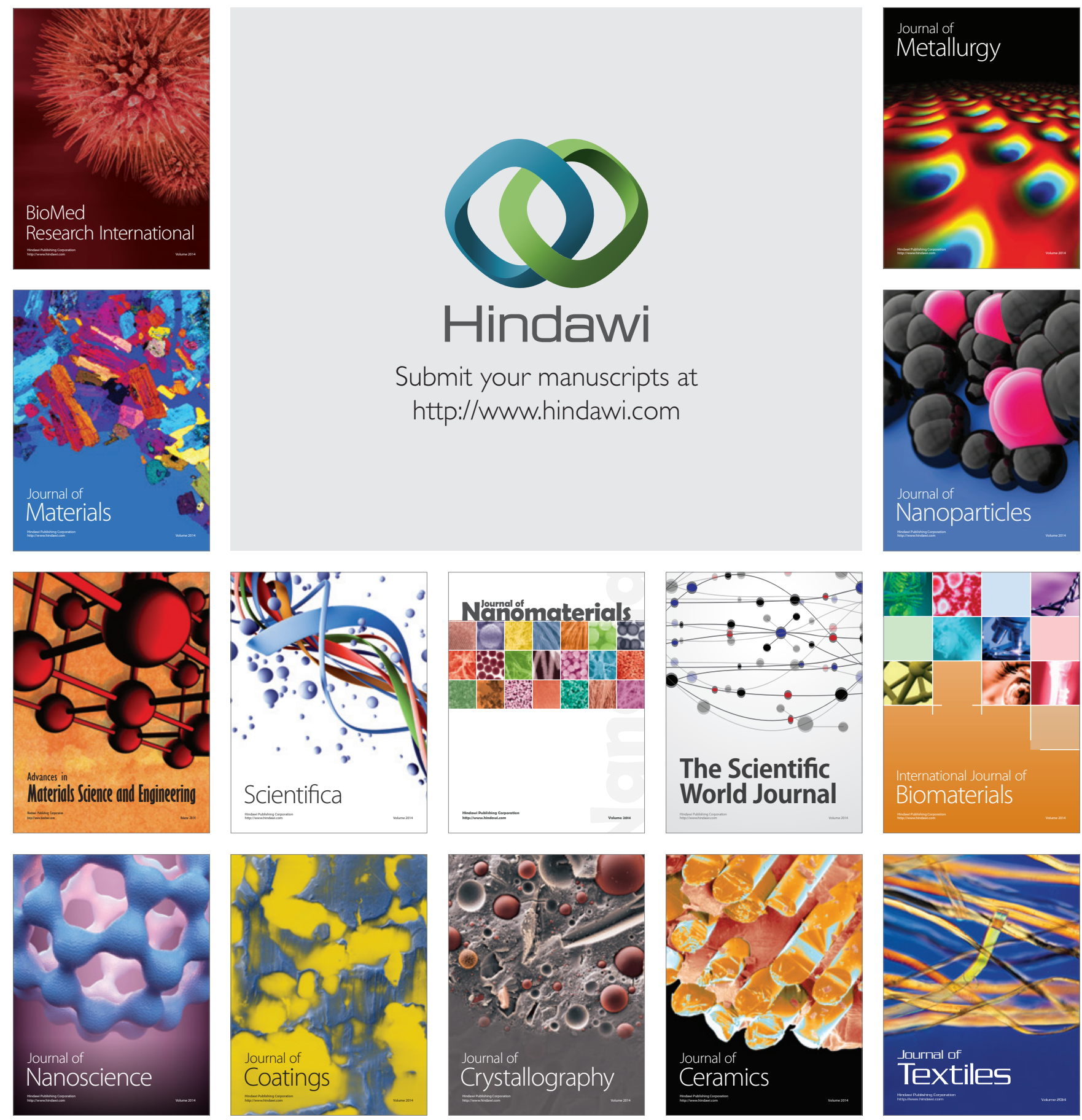